\title{
EXPERIMENTAL AND COMPUTATIONAL INVESTIGATION OF FLOW STRUCTURE IN BUOYANCY DOMINATED ROTATING CAVITIES
}

\author{
Seyed Mostafa Fazeli* \\ Vasudevan Kanjirakkad \\ Christopher Long \\ Thermo-Fluid Mechanics Research Centre \\ School of Engineering and Informatics \\ University of Sussex \\ Falmer, Brighton \\ Email: s.fazeli@sussex.ac.uk
}

\section{ABSTRACT}

The flow and heat transfer inside HP compressor rotating cavities are buoyancy driven and are known to be extremely difficult to predict. The experimental data of Laser-Doppler Anemometry (LDA) measurements inside an engine representative cavity rig is presented in this paper. Traverses using a two component LDA system have been carried out in the shaft bore and the cavity regions in order to map the axial and tangential velocity components. The velocity data is collected for a range of Rossby, Rotational and Axial Reynolds numbers, Ro, $\operatorname{Re}_{\theta}$ and $R e_{\mathrm{z}}: 0.08<R o<0.64,7 \times 10^{5}<\operatorname{Re}_{\theta}<2.83 \times 10^{6}$, $1.2 \times 10^{4}<\operatorname{Rez}<4.8 \times 10^{4}$ and for values of the buoyancy parameter $\beta \Delta \mathrm{T}, 0.284<\beta \Delta T<0.55$. Numerical study using unsteady Reynolds Averaged Navier-Stokes (URANS) simulations have been carried out to elucidate flow details for a few selected cases. The experimental results revealed that the Swirl number $(X k)$ varies from a value $<1$ near the bore to near solid body rotation at increased radii within the cavity. The analysis of frequency spectrum of the tangential velocity inside the cavities has also shown the existence of pairs of rotating and contra-rotating vortices. There is generally satisfactory agreement between measurements and CFD simulations. There is also convincing evidence of two or more separate regions in the flow dominated by the bore flow and rotation.

\footnotetext{
*Address all correspondence to this author.
}

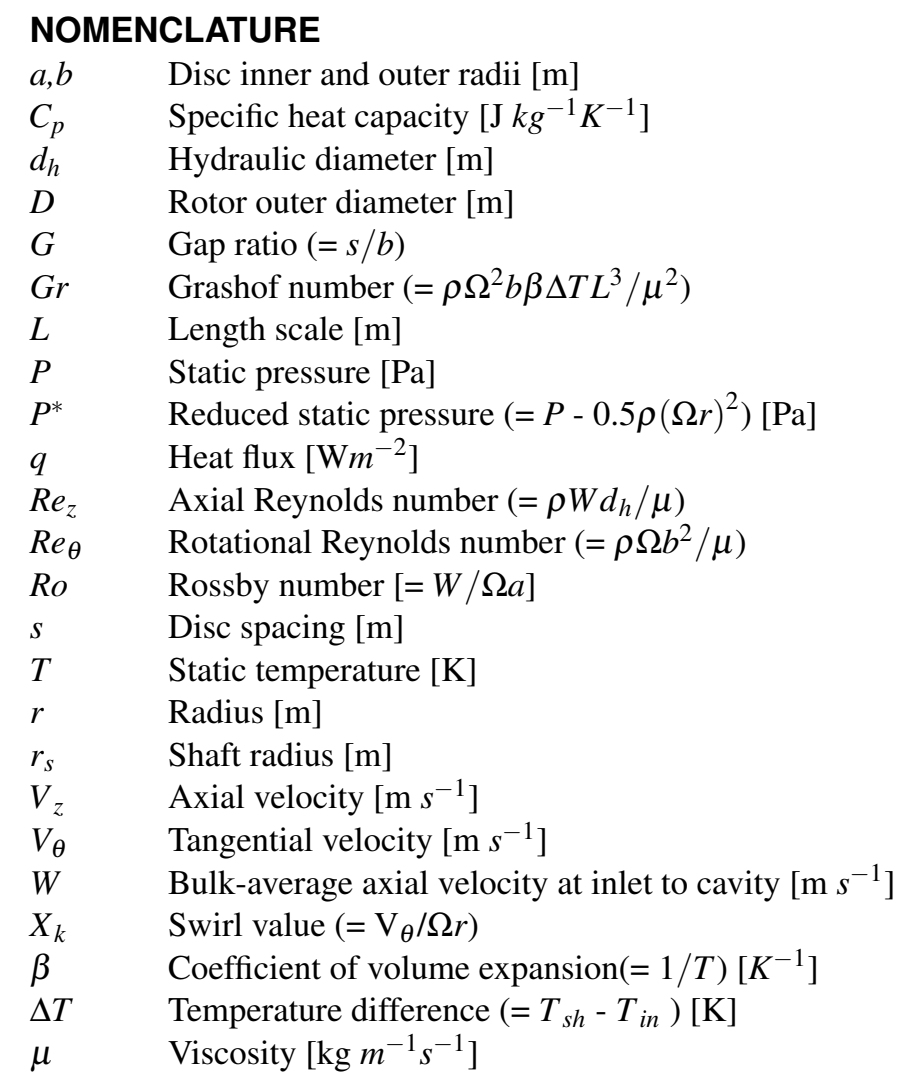




$\begin{array}{ll}\rho & \text { Density }\left[\mathrm{kg} \mathrm{m}^{-3}\right] \\ \Omega & \text { Rotational speed }\left[\mathrm{rad} s^{-1}\right] \\ \Theta & \text { Normalised temperature } \\ & \text { Sub \& Superscripts } \\ a b s & \text { Absolute frame } \\ r & \text { Radial } \\ r e l & \text { Relative frame } \\ z & \text { Axial } \\ \theta & \text { Circumferential }\end{array}$

CFD Computational Fluid Dynamics

LDA Laser Doppler Anemometry

MCR Multiple Cavity Rig

RANS Reynolds-Averaged Navier Stokes

TFMRC Thermo-Fluid Mechanics Research Centre

URANS Unsteady Reynolds-Averaged Navier Stokes

\section{INTRODUCTION}

The high stresses that rotating compressor and turbine discs are subjected to within gas turbine has always presented a challenge to the designers. The variation in temperature gradients resulting from hotter compressor blades and disc rim in comparison with disc bore and cobs during take-off and during landing, cause significant thermal stresses in the discs and consequently affect the flow and heat transfer between the discs and adjacent air [1]. The development of advanced aircraft gas turbine engines is reliant on improvements in thermal efficiency, thrust-to-weight ratio and lower fuel consumption. This is achieved by increasing the turbine entry temperature, cooling down the HP compressor and turbine discs and blades as well as increasing the overall pressure ratio of the cycle and rotational speeds. The turbine entry temperature for such engines surpasses the melting point of the material that the gas path components are made from. Therefore, providing an efficient cooling system is vital to ensure the thermal integrity of the components over the operating life/cycle of the engine. In other words, these engines would not be able to function safely without an internal air system where air is taken from the compressor and then redirected internally to cool the relevant components especially on the turbine side [2]. As seen in Figure 1 a rotating cavity system with axial throughflow has widely been used as a part of internal air system. These cavities are formed between successive compressor (axial) discs in gas turbine engines. The cavities are formed between the rim (or shroud) that supports the compressor rotor blades and the central shaft that rotates relative to the discs. The annular space between the disc bore and the shaft enable axial throughflow of coolant air and the latter could interact with the air within the surrounding cavities. Such flows are known to be extremely complex and hard to predict (analytically and numerically) due to the coupled nature of the disc thermal behaviour and the adjacent fluid flow within the cavity.
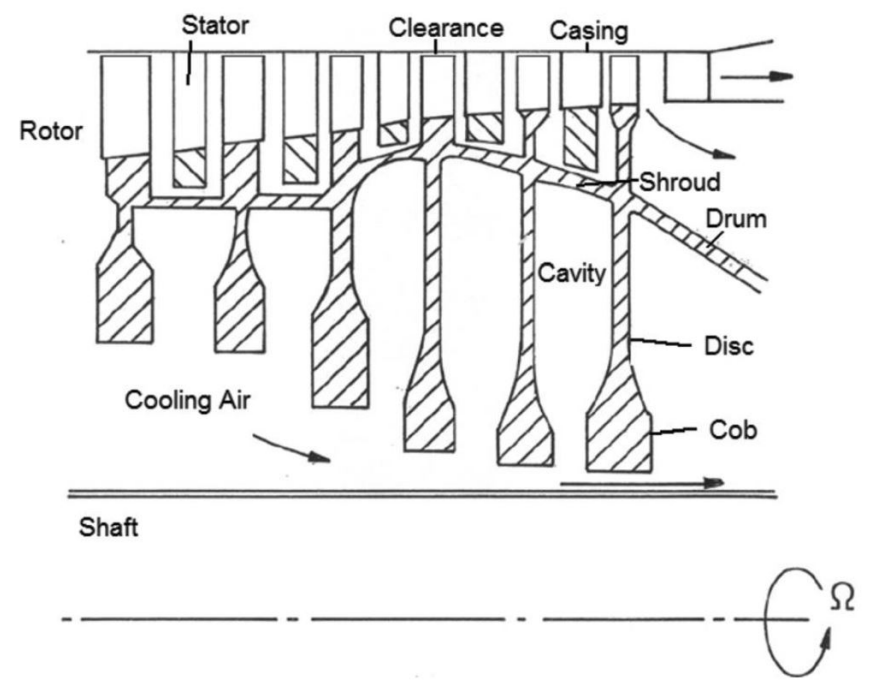

FIGURE 1: Simplified diagram of high-pressure compressor rotor with axial throughflow of cooling air [1]

\section{PREVIOUS WORK}

For a rotating cavity with an axial throughflow, the following dimensionless parameters are used : the axial and rotational Reynolds numbers, $R e_{z}$ and $R e_{\theta}$; the Rossby number $R o$ and since free convection can be significant the Grashof number, $G r$. These are defined as :

TABLE 1: Governing dimensionless parameters for cavity flows

$$
\begin{gathered}
R e_{\mathrm{z}}=\frac{\rho W d_{h}}{\mu} \\
R e_{\theta}=\frac{\rho \Omega b^{2}}{\mu} \\
R o=\frac{W}{\Omega a}=\frac{b^{2}}{2 a\left(a-r_{\mathrm{s}}\right)} \frac{R e_{\mathrm{z}}}{R e_{\theta}} \\
G r=\frac{\rho \Omega^{2} b \beta \Delta T L^{3}}{\mu^{2}} \\
\beta \Delta T=\frac{\left(T_{\mathrm{sh}}-T_{\mathrm{in}}\right)}{T_{\mathrm{in}}}
\end{gathered}
$$

Farthing et al. [3] conducted flow visualisation in an isothermal rotating cavity using four different rigs. The cavity geometry of such rigs are characterised by the cavity gap ratio $(s / b)$ and the bore to shroud radius ratio $(a / b)$. The experiments by the above authors were all carried out at a constant axial Reynolds number $\left(R e_{z}\right)$ of 5000 (indicating turbulent flow at cavity inlet). Four different gap ratios $(G ; 0.533,0.4,0.267$ and 0.133$)$ were employed. They found that for a stationary cavity where Rossby number is infinite and $G>0.4$, a powerful toroidal vortex was present inside the cavity. The results they obtained also revealed 
that the strength of the recirculation inside the cavity was reduced by decreasing the gap ratio and consequently for $s / b=0.267$ and 0.133 , two and three counter rotating vortices were observed respectively. They also realised that the flow structure inside the rotating cavity became non-axisymmetric while one or both of the discs were heated. They described the idea of non-axisymmetric flow structure as cyclonic (low pressure region) and anticyclonic (high pressure region) vortices as shown schematically in Figure 2 .

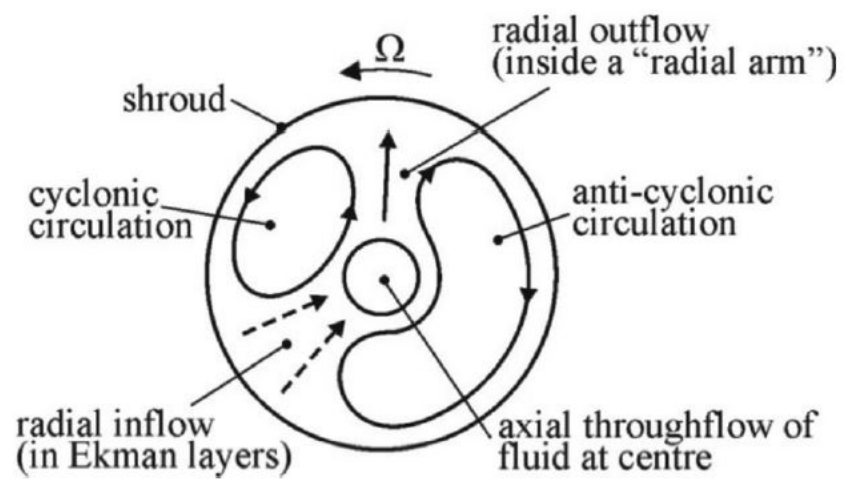

FIGURE 2: Schematic of flow structure in heated rotating cavity with axial throughflow of cooling air [3]

Farthing et al. [3] also carried out flow visualisation and LDA measurements in two rigs for $a / b \approx 0.1$ and, gap ratio $G=0.36,0.267,0.24$ and 0.12 . They observed that cold air entered the cavity radially outwards in a 'radial arm'. The radial arm then formed a pair of vortical structures with opposite sense of rotation. The region that rotated in the same direction as the disc was termed 'cyclonic' and while the one that rotated in the opposite direction to the disc was termed 'anticyclonic'. The two vortex regions were separated by a 'dead' zone corresponding to where the flow left the cavity radially inwards in Ekman layers. They also concluded that the necessary Coriolis forces for the cold air to travel inside the hot cavity by radial arm are generated by the circumferential pressure gradient [1].

Bohn et al. [4] conducted flow visualisation within a rotating cavity and reported a similar flow structure as Farthing et al. [3]. The role of buoyancy on heat transfer in rotating cavities was the focus of Alexiou [2] and their measurements revealed that the flow in rotating cavities can be dominated by free convection, forced convection or both [5,6]. Owen and Powell. [7] carried out LDA and heat transfer measurements in a single cavity rig, with $a / b \approx 0.4$ and $s / b \approx 0.2$ where the downstream disc was heated. A spectral analysis of the LDA measurements revealed a multicell structure including up to three pairs of cyclonic and anticyclonic vortices in the flow field. They also found that al- though there are some exceptions, the number of pairs of cyclonic and anticyclonic vortices was reduced by increasing the rotational Reynolds number at a constant axial Reynold number. Long et al. [8] conducted LDA measurements inside a heated

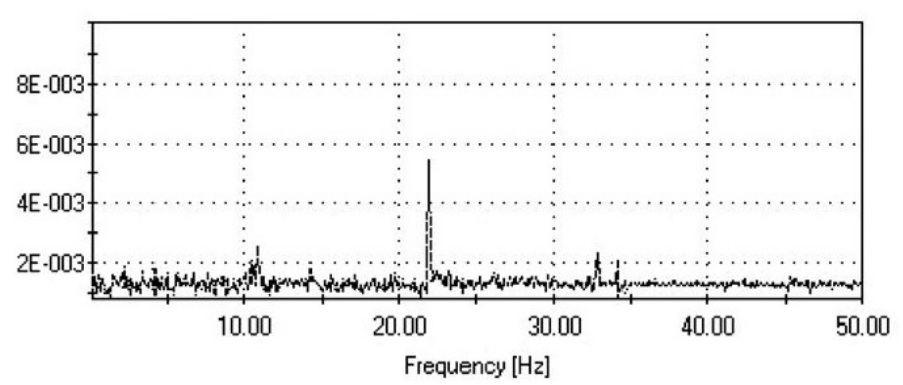

FIGURE 3: Spectral analysis of the tangential component of velocity, (rotational speed of cavity $=10.92 \mathrm{~Hz}$ ) [8]

multiple cavity (consisting of 4 cavities and 5 discs) with axial throughflow where $a / b \approx 0.318$ and $s / b \approx 0.195$ for each cavity. The shroud in this rig was heated by an external flow of hot air within a pressurised outer casing. The LDA system measured the velocities in cavities 3 and 4 whereas temperatures were measured along the walls of cavities 2 and 3 by a limited embedded thermocouples. The frequency spectrum obtained from tangential velocity measurements for mid-plane of cavity 3 at radial location of $r / b \approx 0.765$ showed the evidence of the dominant frequency at approximately twice as the rotational speed of the flow which implied the presence of two vortex pairs around that specific location. The frequency spectral analysis is shown in Figure 3.

Atkins and Kanjirakkad [9] conducted measurements in the same multiple cavity rig as $[2,8]$ but this time with a stationary shaft and the direction of flow through the rig reversed compared to the previous builds. Additionally, in these experiments the shroud was radiantly heated. They measured the steady state temperatures on both sides of the disc separating cavities 2 and 3 which was instrumented by embedded surface thermocouples. The results demonstrated the sensitivity of the radial temperature distributions along the disc with the variation of Grashof number, axial throughflow and rotational Reynolds number for approximately constant Rossby number. For instance, for $R o \approx 5$ and a rotational Reynolds number of $R e_{\theta} \approx 8 \times 10^{4}$ there existed an almost linear dimensionless temperature profile from $r / b \approx 0.4-0.9$. The results also showed that for low Rossby numbers $(R o \leq 1)$ and large Grashof numbers, where the buoyancy effects are expected to dominate, the Nusselt number $(\mathrm{Nu})$ increased with increasing Gr.

Owen and Long [10] published a comprehensive review of buoyancy induced flow in both closed and open rotating cavities with either axial throughflow or a radial inflow of air.

Tang et al. [11] compared the Nusselt numbers and disc tem- 
peratures of the HP compressor rotors predicted from a theoretical model of buoyancy-induced flow in rotating cavities $[12,13]$ with values obtained from the experimental data of [9]. Although there was a good agreement between the theoretical and experimental data of Nusselt numbers and radial distribution of the disc temperatures for most of the 19 test cases with Grashof numbers up to $10^{12}$, the predicted data showed that the Nusselt number can decrease whilst the Grashof number increases. This was attributed to compressibility effects.

Puttock et al. [14] conducted a series of heat transfer experiments in the same multiple cavity rig as [9] with some further modifications. They found that although the shroud Nusselt numbers are dependent upon the shroud Grashof number, it is not affected by the axial Reynolds number variations. A numerical analysis (URANS) was performed by those authors to investigate the cavity flow structure focusing on the region near the shroud. Here, the simulation identified circumferential streaky patterns which the authors referred to as 'Rayleigh-Bénard' structures. No experimental evidence for such structures was shown.

The non dimensional parameters for experimental tests, the results of which are presented in this paper are shown in Figure 4. The red circles show the conditions for which validated numerical simulations are available. Five levels of Rossby numbers have been implemented for the testing and each of them has been accompanied by at least two axial Reynolds numbers except the lowest one. The experimental data from conditions shown by filled squares in Figure 4 are presented in this paper.

Although an increase in rotational Reynolds number with the

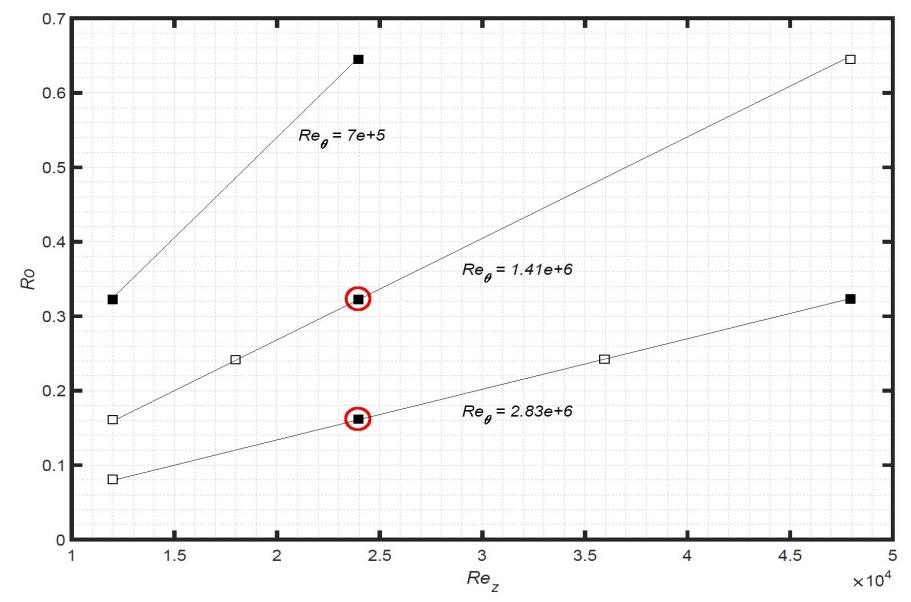

FIGURE 4: Experimental test matrix

constant axial Reynolds number will result in an increase in the buoyancy parameter, $\beta \Delta T$, and consequently Grashof number, since the Rossby number variation is not significant the effect of such changes is expected to be relatively low. For the ten conditions as described in Figure 4, the sensitivity of small variations of Rossby number and buoyancy parameter on the flow structure and temperature profiles is investigated. The buoyancy parameter can be defined as :

$$
\beta \Delta T=\frac{1}{T_{\text {in }}}\left(T_{\text {sh }}-T_{\text {in }}\right)
$$

where, $\beta$ is the coefficient of volume expansion such that $\beta=\frac{1}{T_{\text {in }}}$ and $T_{\text {in }}$ is air temperature at the bore in the middle of the cavity and $\Delta T$ is the difference between the shroud and the cavity inlet temperature $\left(T_{s h}-T_{i n}\right) . T_{s h}$ is the shroud metal temperature. The air and metal temperature thermocouples locations inside the rig will be discussed later in this paper.

\section{TEST FACILITY}

The Sussex Multiple Cavity Rig (MCR) has been used to investigate the heat transfer and flow structure within the disc cavities that are typical of an aero-engine HP compressor. The current test rig is designed to be a $70 \%$ full scale replica of a typical high pressure compressor internal air system.

\section{Rig geometry and specifications}

The MCR facility has been modified several times over the years. The latest modifications were the $5^{\text {th }}$ and $6^{\text {th }}$ builds that have been comprehensively discussed in Puttock [15].

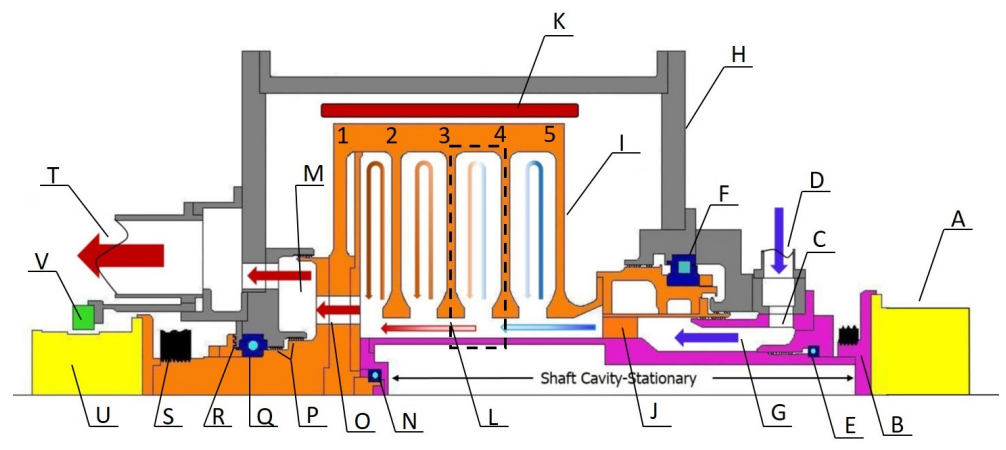

FIGURE 5: Cross-sectional view of the MCR

A cross-sectional view of MCR is shown in Figure 5. Note that the successive discs and cavities are numbered progressively in a direction opposite to that of the throughflow. The cavity of interest in the current paper is cavity 3 that is located between discs 3 and 4 (dashed black rectangle). The purple sections illustrate the new stationary shaft where the LDA window is located, the grey region represents the outer drum and other stationary components, the orange section is the rotating assembly and the red region indicates the radiant heater array. The cross-sectional 
view presented in Figure 5 shows an earlier design of the disc cobs. It should be noted that the LDA tests and CFD results reported in this paper made use of marginally different cob shape as seen later in Figures 7-11.

The rotating assembly is manufactured from Ti-6Al-4V titanium alloy (Fig.5.I) which is supported by the bearings (Fig.5.Q). The outer radius (b) of the cavities is $220 \mathrm{~mm}$ while the inner radius (a) is $70.1 \mathrm{~mm}$, so that the radius ratio $(a / b)$ is 0.318 . The disc spacing $(s)$ is $42.9 \mathrm{~mm}$ and the gap ratio $(G)$ is 0.195 . The central shaft has a radius $\left(r_{\mathrm{s}}\right)$ of $52 \mathrm{~mm}$ and hydraulic diameter $\left(d_{\mathrm{h}}\right)$ of $36.2 \mathrm{~mm}$ is manufactured from mild steel (Fig.5.B). The shaft is held stationary for all runs. The axial throughflow enters the rig through two $30 \mathrm{~mm}$ diameter pipes (Fig.5.D) that are perpendicular to the axial direction. The flow then enters an annular plenum in the circumferential direction then lead the throughflow air into an annular duct (Fig.5.G) through twelve holes that are of $24 \mathrm{~mm}$ diameter each (Fig.5.C). Before entering the cavity bore region the air then passes between six rotating blocks (rectangular, $10 \mathrm{~mm}$ wide) (Fig.5.J). This is an attempt to replicate the exit flow from the bore region where it leaves through a rotating end plate containing 6 holes of $25 \mathrm{~mm}$ diameter each (Fig.5.O).

A two stage, screw type, Atlas Copco ZT250 compressor has been used to supply the throughflow air. The air leaving the compressor is directly led to an Atlas Copco air dryer to remove moisture. To pressurise the air inside the rig a butterfly valve is installed downstream of the rig exhaust. This in turn allows a system of internal labyrinth seals to work effectively to ensure that the flow path is appropriately sealed and any leakage is negligible. A calibrated venturi meter installed in the inlet pipe work upstream of the rig measures the mass flow rate. The mass flow rate can be adjusted using a LabVIEW based code that not only sets up the rig running conditions but acquires and records experimental data. To simulate the hot flow in the annulus of the high pressure compressor on the MCR, an array of radiant heaters is located circumferentially around the outer drum (Fig.5.K). Although the system is capable of heating the rotor shroud up to $250{ }^{\circ} \mathrm{C}$, the temperature was never allowed to exceed $230{ }^{\circ} \mathrm{C}$ in order to avoid overheating of the embedded instrumentation. The rotational speed of the rotor assembly is measured by a magnetic pickup probe.

\section{Instrumentation}

Glass fibre insulated K-type thermocouples with wire diameter of $0.25 \mathrm{~mm}$ are used to measure the temperatures in the rotating frame of reference. To reduce the conduction errors, the thermocouples are embedded circumferentially along a line for at least ten wire diameters. The nominal diameter of the thermocouple beads is $0.4 \mathrm{~mm}$. The installation procedure is described in Atkins and Kanjirakkad [9]. A simple 1-D model of the thermal disturbance due to the embedding error is studied by Alexiou [2] and Atkins and Kanjirakkad [9]. Results show errors of the order
TABLE 2: Key to Figure5

\begin{tabular}{cl}
\hline \hline A. & Shaft telemetry unit \\
B. & Central shaft \\
C. & Radial transfer holes \\
D. & Bore flow inlet \\
E. & Inter-shaft bearing \\
F. & Axial oil fed roller bearing \\
G. & Inlet cavity \\
H. & Outer drum \\
I. & Rotating assembly \\
J. & Bore inlet flow restriction \\
K. & Radiant heater \\
L. & Central rotor disc \\
M. & Exit cavity \\
N. & Shaft location bearing \\
O. & Bore flow exit holes \\
P. & Inner grease holes \\
Q. & Grease-pack rotor bearing \\
R. & Oil seal \\
S. & Rotor pulley bely \\
T. & Rig exhaust \\
U. & Rotor telemetry unit \\
V. & Rotor telemetry antenna \\
\hline
\end{tabular}

of $0.1 \mathrm{~K}$ for representative radial temperature gradients.

To calibrate the data acquisition chain including the thermocouples, cold junction references, amplifiers and acquisition cards, the comparison against a national laboratory standard reference system based on an Isotech 915 parallel tube oil bath, an Isotech SPRT and TTI-2 resistance thermometry measurement system is implemented. The data acquisition procedure is comprehensively described by Atkins and Kanjirakkad [9] and is repeated briefly in this paper. The calibration procedure gives a comparison uncertainty of $\pm 20 \mathrm{mK}$ which is an order of magnitude lower than the uncertainty of the thermocouples. The calibration data analysis indicates that the typical single point uncertainties of the thermocouples and cold junctions are in the region of $\pm 0.1 \mathrm{~K}$. A 92 channel Datatel radio telemetry system is used to record the rotating frame thermocouples (Fig.5.U). The telemetry unit, within it, has six individual modules connected in a serial bus. Each unit has a dedicated Platinum Resistance Thermometer (PRT) for the cold junction reference. The recording frequency is $3 \mathrm{~Hz}$. As mentioned in Atkins and Kanjirakkad [9], the errors due to this data acquisition cannot be considered normal in distribution so by adding the error sources, the total worst case uncertainty can be estimated of approximately $\pm 0.5 \mathrm{~K}$ and there is no reduction in uncertainty through averaging.

Eighteen air and metal thermocouples are accommodated circumferentially on the shaft with $90^{\circ}$ tangential spacing and at 
nine axial locations along the shaft. A Datatel radio telemetry system is used to acquire data of the shaft thermocouples (Fig.5.A). Both shaft thermocouples and the rotating frame ones are glass fibre insulated K-type thermocouples. The air thermocouples are located at an $r / b$ of 0.25 . As explained in Puttock and Rose [16], the shaft thermocouples have the ability to detect the unsteady thermal wakes of the upstream blocks under specific conditions. The thermocouple wires are routed along the inner shaft surface on the way to a Datatel radio telemetry. The cold junction referencing PRT used here are similar to the ones used for the measurement of the rotating frame thermocouples and they give the same bias error for uncertainty analysis. Ktype metal thermocouples connected to an Agilent 34970A are used to measure the stationary frame temperatures.

The pressure adjacent to the stationary shaft is measured by a group of nine static pressure tappings. A 16 channel Scanivalve Digital Sensor Array (DSA) 3217 is used for pressure measurements. The rig vibration during the run is measured by an ADXL345 three-axis accelerometer low frequency vibration sensor which is connected with an Arduino Uno board.

\section{LDA Information}

Laser Doppler Anemometry (LDA) was used to measure velocity components in the Multiple Cavity Rig. This method of measurement does not need calibration as the output burst signal is a function of velocity, and is able to measure reverse flows with a suitable frequency shifting technique. A Cut-away view of the LDA probe positioning inside the rotating cavities is shown in Figure 6. The described LDA equipment and 'inshaft'

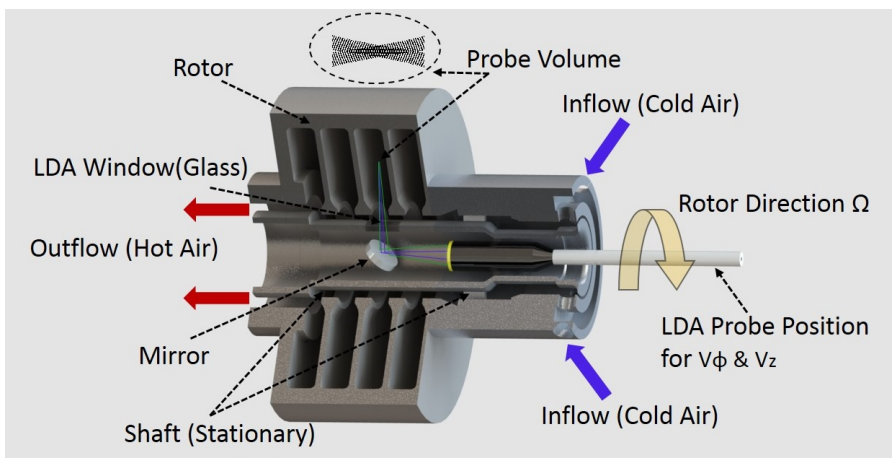

FIGURE 6: Cut-away view of the LDA probe positioning inside the rotating cavities

choaxial traverse system have been used since Build 2 of MCR and were previously mentioned in [17]. The Dantec 2-D LDA system emits two colour laser beams in the green colour mode $(514.3 \mathrm{~nm}$ wavelength) and blue $(488.3 \mathrm{~nm})$ at a power output of up to $1 \mathrm{Watt}$. The frequency shift of $40 \mathrm{MHz}$ is added by a Bragg cell while the laser source is split. The $27 \mathrm{~mm}$ diameter FiberFlow probe allowed the transmission of the measurement beams in a factory aligned sealed casing. The front optic (lens) is modified to provide a $100 \mathrm{~mm}$ or $250 \mathrm{~mm}$ focal length to the probe depending on radial location of measurement and the focusing area.

A $4 \mathrm{~mm}$ length of probe volume is produced by a $15 \mathrm{~mm}$ beam spacing lens with $250 \mathrm{~mm}$ focal length. This relatively long probe volume can affect the ability of measurements near the walls, shrouds and in the annulus grid. To overcome this, the $15 \mathrm{~mm}$ beam spacing lens with $100 \mathrm{~mm}$ focal length is used to measure the velocity components along the annulus region as well as the cobs. A Dantec 9010 six jet atomiser using olive oil to produce seeding particles with the size of approximately $1 \mu \mathrm{m}$, is employed. The fringe spacing is roughly 8 times that of the typical seeding particle and consequently multiple measurements could occur frequently. Therefore the seeding density was kept to a minimum for an acceptable validation data rate. In order to reduce glare and optical noise while measuring, the internal surfaces of the rig is painted matt black. The optical access window is made of BK7 optical grade glass treated with an anti reflection coating for the $480-520 \mathrm{~nm}$ wavelength range. The scattered light signals were sent to the photomultipliers from a probe.

The Doppler signals, are processed by a DANTEC BSA70 Burst Spectrum Analyser. The photomultiplier surge is automatically protected by signal processor as a hardware Fast Fourier Transform algorithm can handle and validate the Doppler bursts at rates of up to $100 \mathrm{kHz}$. A Baumer BHG06-25W360 encoder is mounted at the end of the rig and close to the rotor telemetry antenna. TTL level pulse is generated by the encoder to be synchronised to the LDA signal in the signal processor. The encoder could provide 360 pulses per revolution, the reset pulse was used as in normal practice in rotating machinery where the rotational speed can be considered steady. In parallel, the angle stamp data can be recorded.

The incident laser beams and reflected signals are diverted onto the probe using a $45^{\circ}$ mirror located on the centre line of the rig. The probe volume is positioned by two concentric tubes that are traversed axially: one for the probe, the other for the mirror. The LDA measuring grid point for annulus includes over 200 measuring points by using an optical lens with $100 \mathrm{~mm}$ focal length whereas a lens with $250 \mathrm{~mm}$ focal length is used to record the velocity components at 30 measuring points along the mid planes inside the cavities. For some specific runs three $r-\phi$ planes are used to record the LDA data in each cavities. The accuracy of placement of the axial and radial locations is considered to be $\pm 0.5 \mathrm{~mm}$.

\section{NUMERICAL SETUP}

A numerical study using URANS was carried out in order to aid the interpretation of the flow field for two rotational Reynolds 
numbers with the axial Reynolds numbers kept constant for both cases. The current CFD modelling has included the entire upstream flow domain and two cavities to reach to the best agreement with the experimental conditions. ICEM-CFD 17.1 and Ansys Fluent 19.2 are employed to generate high resolution grid and to simulate the turbulent flow within the MCR. A 2-D multi block grid including $2.5 \times 10^{4}$ nodes was created and revolved over 360 degrees in the circumferential direction around the rig axis in order to generate a high resolution 3D domain for each cavity. There are about 9 million grid points within each cavity. The method of Dweik et al. [18] was used to create 25 points in the first $2 \mathrm{~mm}$ normal to the surface with the first point located $0.005 \mathrm{~mm}$ from the walls. A logarithmic bunching algorithm is then used in order to reach a high resolution boundary layer with $y^{+}<1$ on the cavity walls and shroud region. The meridional plane of the numerical domain is shown in Figure 7.

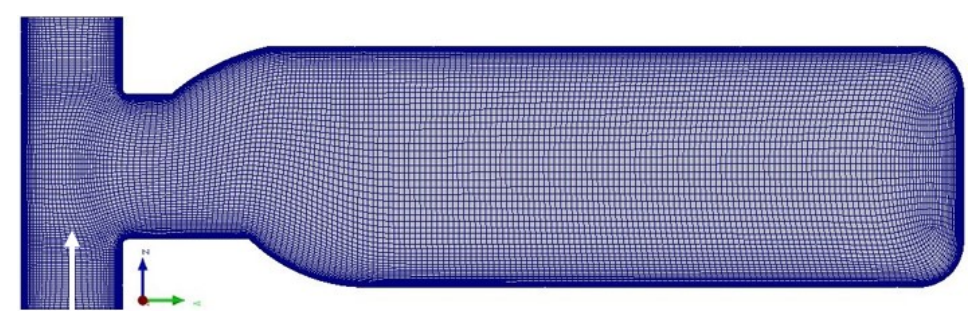

FIGURE 7: Meridional view of the computational domain

The initial conditions were the converged steady-state results for the transient calculations discussed in this paper. The $\mathrm{k}-\omega$ SST turbulence model has been used for the simulations which covers both $\mathrm{k}-\varepsilon$ and $\mathrm{k}-\omega$ models and benefits from automatic near wall treatment that switches to low-Reynolds number formulation in the viscous sub-layer [19]. The measured temperatures from the experiments are used to define wall boundary condition on the shaft surface and all cavity walls. As the data was recorded at a frequency of $3 \mathrm{~Hz}$, the temperatures were averaged over a minute from thermally steady sate modes which in turn helps to reduce stochastic differences. An isothermal wall boundary conditions was used for the upstream section, these temperatures were extracted numerically from measured conditions. A total pressure inlet boundary was used while the static pressure was applied for outlet to match the mass flow rate.

The numerical time step of the transient simulations is equivalent to $1^{\circ}$ of a revolution and the solution was run for over 50 complete revolutions. Convergence of each time step was completed when the equation residuals reached below $1 \times 10^{-4}$. The time taken for each solution was about 28 days using 96 CPUs on the university of Sussex High Performance Computer. The non-dimensional parameters for the runs are as follows: $R e_{z}=$ $2.4 \times 10^{4}, 1.4 \times 10^{5}<R e_{\theta}<2.83 \times 10^{5}, 0.34<\beta \Delta T<0.38$.

\section{RESULTS AND DISCUSSION}

The data from three different experiment test cases (as presented in Figure 4) are discussed in this section. The sensitivity of the radial distribution of the disc non-dimensional temperature $\Theta$ and the flow structure as recorded by LDA with respect to Rossby number (Ro) and the buoyancy parameter $(\beta \Delta T)$ are presented. The non-dimensional disc temperature is defined as:

$$
\Theta=\frac{T(r)-T_{\text {in }}}{T_{\text {sh }}-T_{\text {in }}}
$$

where, $T(r)$ is the local temperature, $T_{s h}$ is the shroud metal temperature and, $T_{\text {in }}$ is the air temperature near the shaft at the bottom of the cavity. The thermocouple locations for these measurement are as shown in Figure 8. The black dots indicate the metal thermocouples whereas the red triangle shows the shaft air thermocouple (note that the cavity in discussion here is cavity 3, located between discs 3 and 4, as shown in Figure 5).

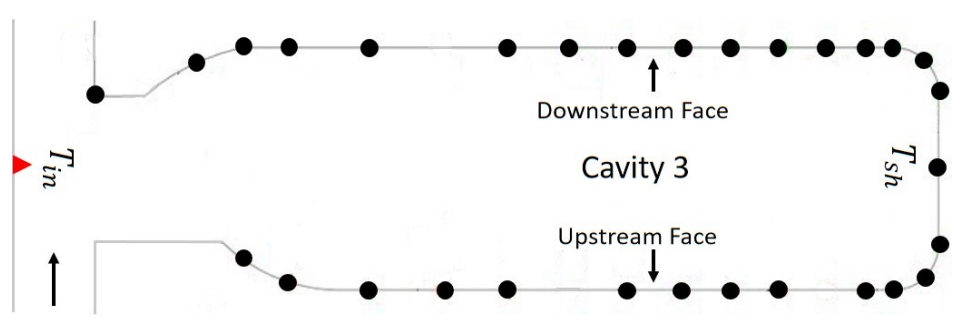

FIGURE 8: Distribution of thermocouples in cavity 3

All experimental data presented in this paper is obtained from steady state of the thermal conditions. The steady state mode was achieved once the variation of the temperatures shown by the thermocouples are less than $0.2 \mathrm{~K}$ within 5 minutes. It should also be noted that the LDA results discussed in this paper are the time-averaged results.

\section{Constant Rossby Number}

Figure 9 shows the measured values of normalised axial velocity $\left(V_{\mathrm{z}} / W\right)$ for a number of tests with $R o=0.32$. The high spatial density of measurements in the bore region have allowed contour plots to be produced and these are shown in Figure 9a and Figure 9b. Figure 9c shows the radial variation of normalised axial velocity taken in the mid-plane of cavity 3 . In the region of the disc bore $(0.24<r / b<0.32)$ the LDA measurements shown in both contour plots and the graph are consistent with an expected value of $V_{\mathrm{z}} / W \approx 1$. The graph (Figure 9c) shows this velocity to decay rapidly with increasing radius and for $r / b>0.365$, there is evidence of only a low magnitude of normalised axial velocity. One notable exception to this is the test at $\operatorname{Re}_{z}=2.4 \times 10^{4}$ and $\operatorname{Re}_{\theta}=1.4 \times 10^{6}$, where at $r / b \approx 0.81$, 
$V_{\mathrm{z}} / W \approx-0.5$. Although this may appear suspicious, this particular data point is repeatable and has been closely inspected and on balance is believed to be representative of a time-average of the axial velocity at this radial location for the following two reasons. Firstly, the measurements here show a spread of the $R M S$ values that is comparable to the magnitude of the measurement itself; indicative of some significant variation of velocity within the flow at this location. Secondly, there is evidence from the CFD simulations of a small sector of significant axial velocity at this radial location and outside this sector $V_{\mathrm{Z}} / W \approx 0$. Although all the three tests shown in Figure $9 \mathrm{c}$ were carried out with $R o=0.32$, it would appear that at the highest value of $R e_{\theta}$, the axial velocity for $r / b>0.365$ is virtually zero.

The contour plots (Figures 9a and 9b) provide more detail of the flow field in the bore region. The decay in axial velocity with increasing radius is seen to occur across the width of the cavity. However, and not surprisingly, there is some asymmetry in the flow as it enters each cavity with a tendency for the flow to impinge on the bore of the disc in the downstream direction. There is also evidence of flow separation under the bore of disc 5 which is considered to be caused by the tapered inlet geometry (see Figure 5). At the higher value of $R e_{\mathrm{z}}$ (Figure 9b) there is also evidence that this separation occurs under the bores of discs 3 and 4 as well.

The axial velocity contour lines in Figures $9 \mathrm{a}$ and $9 \mathrm{~b}$, show that, the bore flow locally enters each of the disc cavities near the downstream cob face and leaves the cavity near the upstream cob face. However, this is a time-averaged image over the duration of LDA data capture. In reality, one could expect the radial migration into and out of the cavity to be non-uniform over the circumference. For instance, the bore flow could enter the cavity near the downstream cob face for part of the circumference whereas in other parts it may leave the cavity along this face. The latter scenario would cause the exiting flow to separate locally from the downstream cob as it re-enters the bore region thus creating a separated region below the cob. In the LDA measurements, realised over several revolutions of the disc, these separated regions would be captured as an averaged feature as seen in Figures $9 \mathrm{a}$ and $9 \mathrm{~b}$. The separated region are seen to become larger as the axial and circumferential Reynolds numbers are increased in tandem.

Figure 10 shows a vector plot from the CFD prediction of the flow in the bore region with $R e_{\mathrm{Z}}=2.4 \times 10^{4}$ and $R e_{\theta}=1.4 \times 10^{6}$ (Case 1). There is encouraging agreement between the bore flow directions as suggested by contour plot in Figure 9a and the instantaneous vector plot presented in Figure 10. The asymmetry in the flow entering the cavities and the separation under the bores of the disc 5 are also visible.

Figure 11 shows the variation of measured values of normalised tangential velocity $X_{\mathrm{k}}\left(X_{\mathrm{k}}=V_{\theta} / \Omega r\right)$ obtained from the same tests as in Figure 9.

In all tests shown here, the swirl increases with increasing ra- dius in the bore region, then reduces as the flow enters the cavity. Inside the cavity $(r / b>0.32)$, the swirl reaches a minimum in the region of $0.44<r / b<0.50$ and then increases with increasing radius to achieve close to solid body rotation in the vicinity of the shroud. This may suggest the existence of at least two separate regimes: one near the bore which is dominated by the effects of bore flow or others, radially outward from this dominated by rotation. The radial location of the local minimum in $X_{\mathrm{k}}$ appears to move radially inward as both $R e_{\theta}$ and $R e_{\mathrm{Z}}$ increase, which not only lends some support to this hypothesis but also suggests that the Rossby number alone is not a unique parameter for the flow field. The contour plots shown in Figures 11a and $11 \mathrm{~b}$ show a localised area of high swirl on the upstream side of each disc bore and a corresponding low value on the downstream side. This would suggest a localized area of recirculation in the bore region with net movement of flow radially inward next to the upstream side and radially outward next to the downstream side which is evident from the vectors obtained from the CFD prediction shown in Figure 10.

\section{Non-dimensional Temperature for Constant Rossby Number}

Figure 12 shows the dimensionless temperature profiles within cavity 3 for constant Rossby number $(R o=0.32)$. For all test conditions shown in Figure 12, the downstream face of the cavity (disc 3) is seen to be hotter than the upstream face (disc 4). This is expected since as the throughflow air travels from inlet of the rig to the exit, it picks up more heat from the discs, which makes the air and metal surface progressively hotter. For the downstream face of the cavity (disc 3 ), there is a marked difference in the radial variation with $\Theta$ for $r / b<0.7$ compared with $r / b>0.7$. For $r / b<0.7$, the variation is almost linear, whereas for $r / b>0.7$ it is not. This is in contrary to the radial variation of $\Theta$ for the upstream face of the cavity (disc 4), which displays a non-linear behaviour. These differences are attributed to :

(i) The greater influence of bore flow on the downstream disc.

(ii) The existence of two separate regions of flow one for $r / b<$ 0.7 and the other for $r / b>0.7$.

The different sensitives of $\Theta$ to $R e_{z}$ for upstream and downstream discs would also appear to provide evidence to support $(i)$.

Although the LDA measurements reported in the previous section indicate that direct impingement of the bore flow is limited in $r / b<0.38$. It would appear from the discussion of $\Theta$ presented above that there is some secondary effect; possibly the impingement of the bore flow and the recirculation shown in Figure 10 acts as a heat sink for the flow field further into the cavity. 

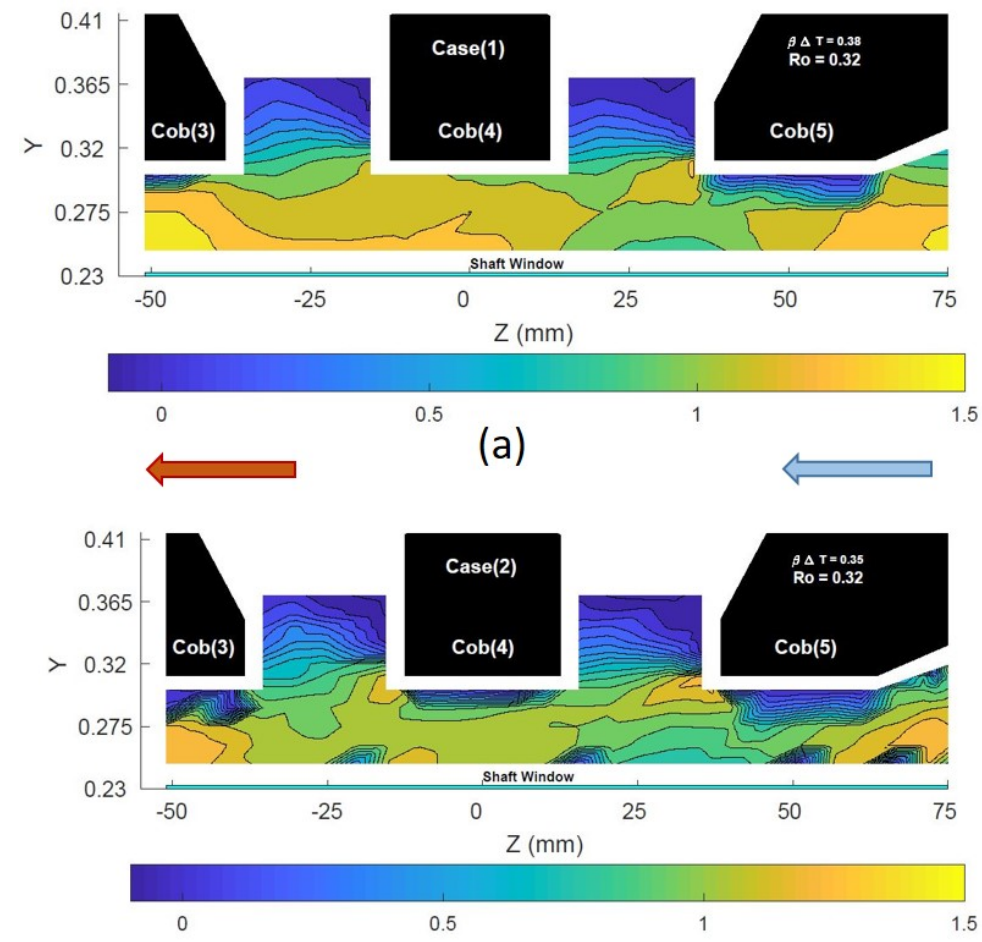

(b)

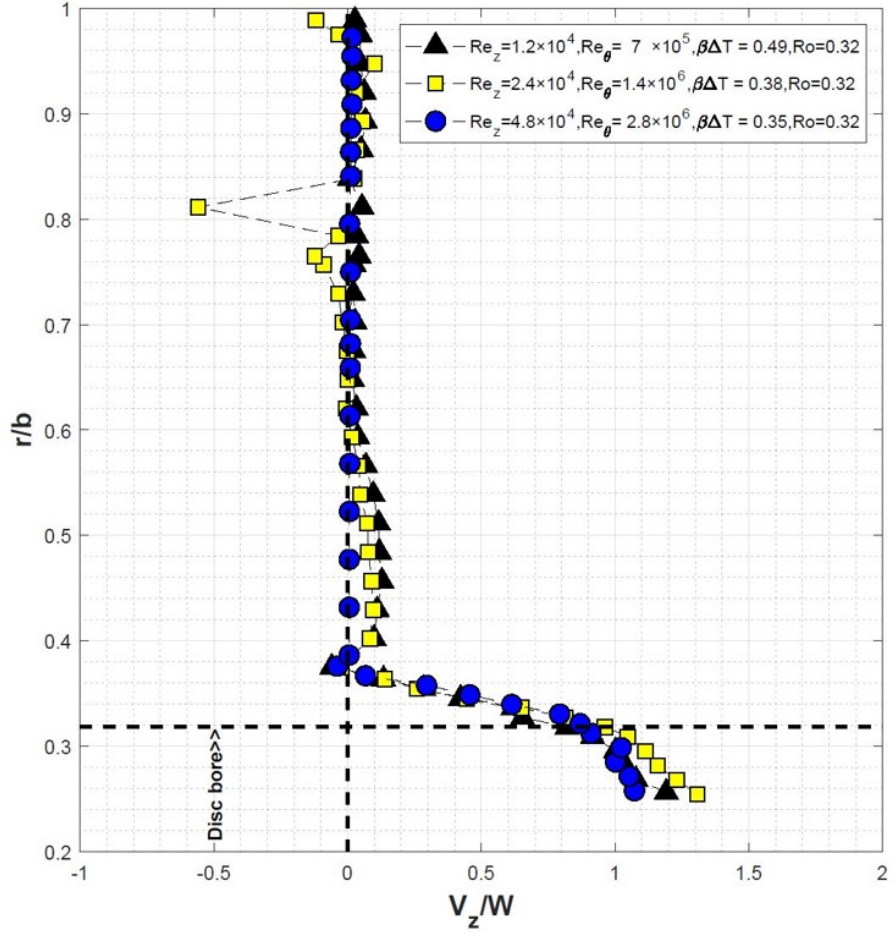

(c)

FIGURE 9: LDA results of normalised axial velocity (contour plots and graph) : $R o=0.32,1.2 \times 10^{4}<R e_{z}<4.8 \times 10^{4}, 7 \times 10^{5}<$ $\operatorname{Re}_{\theta}<2.83 \times 10^{6}, 0.35<\beta \Delta T<0.49$

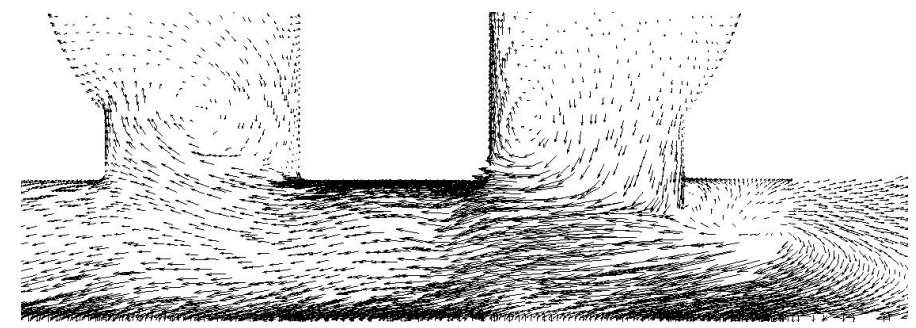

FIGURE 10: Computed relative velocity vectors $\left[\mathrm{ms}^{-1}\right]: R o=$ $0.32, R e_{\mathrm{Z}}=2.4 \times 10^{4}, R e_{\theta}=1.4 \times 10^{6}$ and $\beta \Delta T=0.38$ in the meridional view (corresponding to the normalised axial velocity contour plot- Case 1)

\section{Spectral Analysis of the LDA Tangential Component of Velocity}

Spectral Analysis of the tangential component of velocity $\left(V_{\theta}\right)$ is presented in this section for a fixed axial Reynolds number but varying rotational Reynolds numbers (and hence varying Rossby numbers). As discussed in previous sections, the heated rotating cavity with axial throughflow can create pairs of vortices in $r-\phi$ plane (Fig.2). Farthing et al. [3] showed evidence of existence of these vortices using flow visualisation. Owen and Powell [7] and Long et al. [8] calculated the frequency spectrum from velocity measurements that also suggested the existence of such rotating structures. It is, therefore, thought that there is some merit in presenting the spectral analysis of velocity data that was captured near the cavity mouth. This was achieved by calculating the power spectral density from the raw tangential velocity data by using a Fast Fourier Transform (FFT) technique. Each measured value is attained by averaging 2000 of raw velocity samples that are equally spaced in time. To achieve this, sample/hold and resampling of the instantaneous data is done before the actual FFT analysis. The frequency spectrum obtained for three different cases with the respective range of Rossby number $(R o)$, rotational Reynolds number $\left(\operatorname{Re}_{\theta}\right)$ and axial Reynolds number $\left(R e_{\mathrm{z}}\right)$ : $0.16<R o<0.64,7 \times 10^{5}<\operatorname{Re}_{\theta}<2.83 \times 10^{6}, \operatorname{Re}_{\mathrm{Z}}=2.4 \times 10^{4}$ and the buoyancy parameter $(\beta \Delta T)$ range, $0.34<\beta \Delta T<0.55$ is shown in Figure 13. The analysis has been carried out in the mid plane $(z / s=0.5)$ of the cavity 3 at a radial location of $r / b=0.4$. In Figure 13, $\mathrm{f}_{0}$ represents the rig rotational frequency which for the three cases presented are approximately $33,66.5$ and $133 \mathrm{~Hz}$. There is a spike in each case which occurs at a frequency of $2 \mathrm{f}_{0}$ (twice the frequency of solid body rotation).

For cyclonic and anticyclonic zones of circulation of the type shown in Figure 2, at the outer radius of the disc, a cyclonic circulation will exhibit higher tangential velocity than solid body $\left(V_{\theta}>\Omega r\right)$ rotation whereas an anticyclonic circulation region would exhibit a lower velocity than solid body rotation $\left(V_{\theta}<\right.$ $\Omega r$ ). Towards the inner radius of the disc, close to the bore, the opposite behaviour exists. In one full revolution of such a struc- 

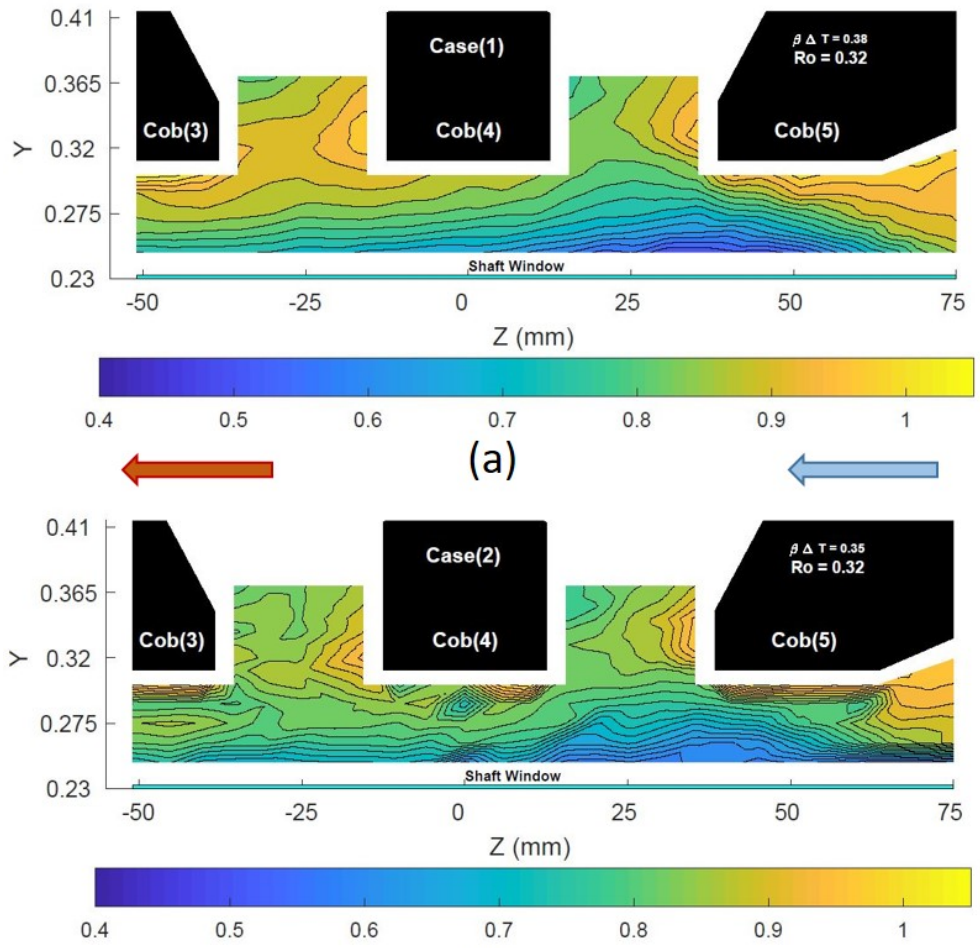

(b)

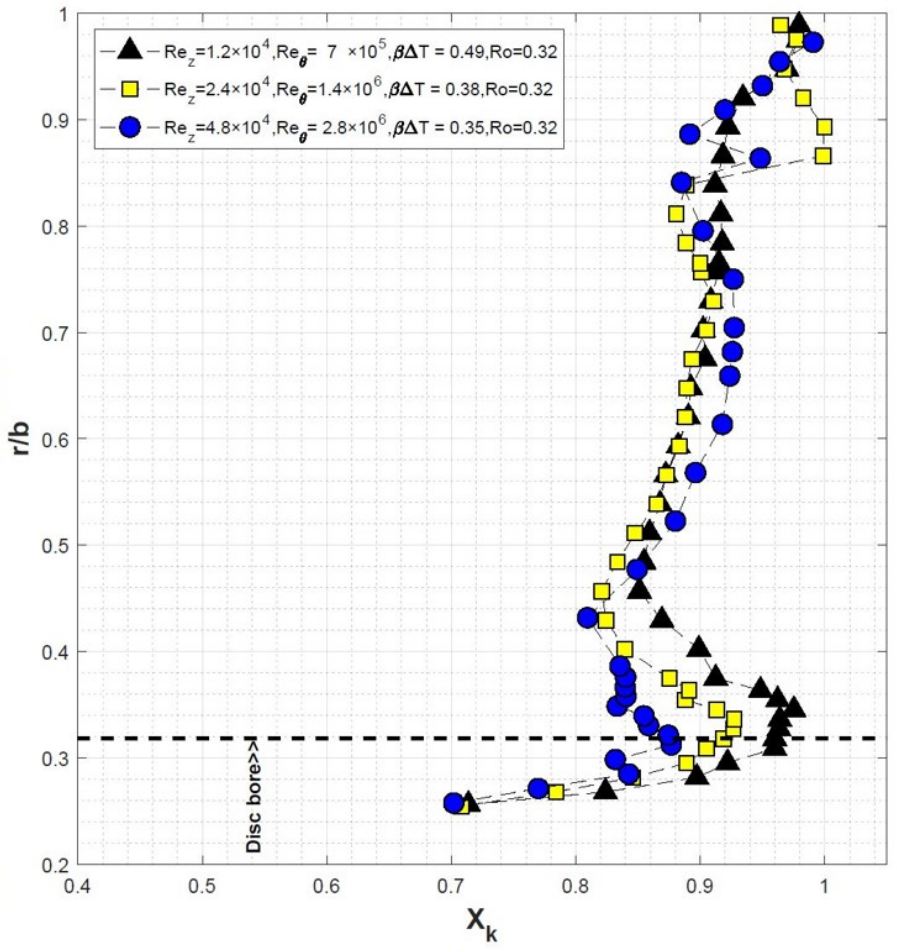

(c)

FIGURE 11: LDA results of $\mathrm{X}_{\mathrm{k}}$ value (contour plots and graph) : $R o=0.32,1.2 \times 10^{4}<\operatorname{Re}_{z}<4.8 \times 10^{4}, 7 \times 10^{5}<\operatorname{Re}_{\theta}<2.83 \times 10^{6}$, $0.35<\beta \Delta T<0.49$

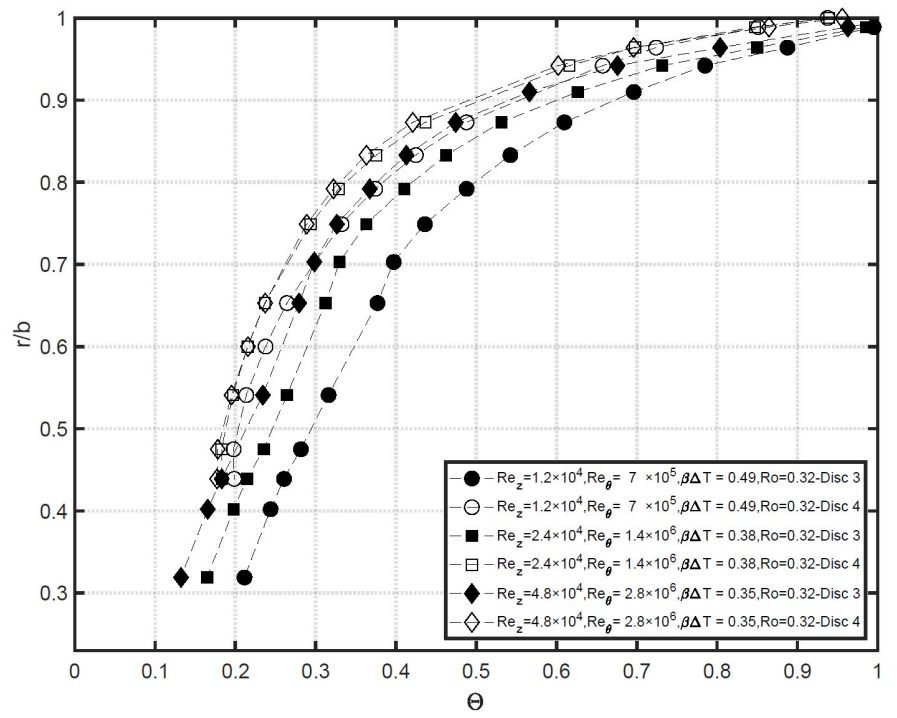

FIGURE 12: Dimensionless temperature $(\Theta): R o=0.32,1.2 \times$ $10^{4}<R e_{z}<4.8 \times 10^{4}, 7 \times 10^{5}<R e_{\theta}<2.83 \times 10^{6}, 0.35<$ $\beta \Delta T<0.49$

ture around the disc axis, therefore, there exists one peak and one trough in the tangential velocity temporal signal collected from a fixed tangential location. A signal with the frequency of approximately the rotational speed of the flow is created when

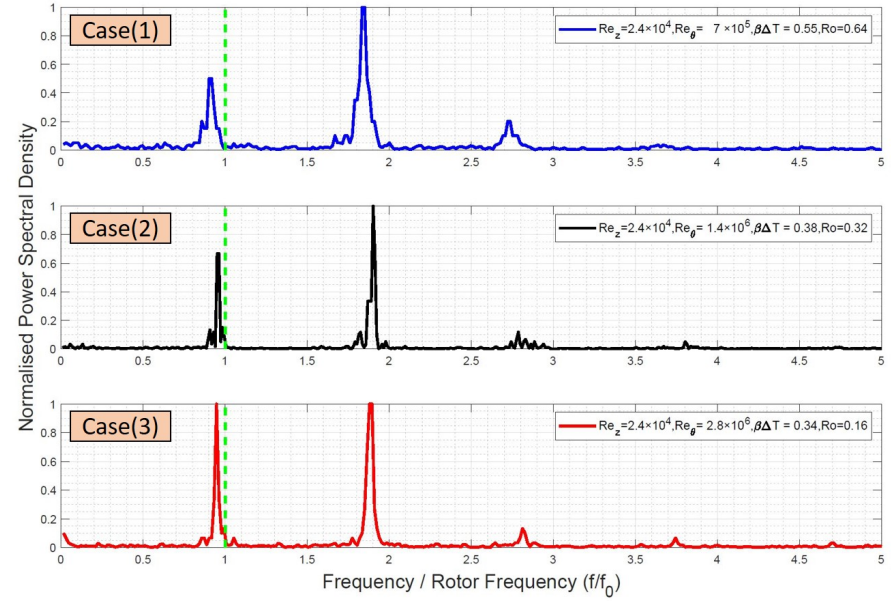

FIGURE 13: Frequency spectrum obtained from tangential velocity measurements in the cavity 3 mid plane at a radial location of $r / b=0.4$

a full rotation happens, however both experimental and numerical studies confirm that the tangential velocity can alter between 0.95 and 1.05 of the rotational speed $( \pm 5 \%$ slip of the flow to the wall). The dominant frequency would be doubled if two pairs of vortices exist and three times if three pairs occur. The numerical analysis of case 3 from Figure 13 shows the existence of at least 
two pairs of vortices as plotted in Figure 14. This agrees with the data presented in the frequency spectrum in Figure 13 where a dominant spike was visible at twice the disc rotational frequency in each case. In figure 14, the anticyclonic circulations are denoted by A1, A 2 and cyclonic circulations by $\mathrm{C} 1, \mathrm{C} 2$. The white dot represents the radial location of the spectral analysis whereas the white dashed circle illustrates the bore region as shown in Figure 14.

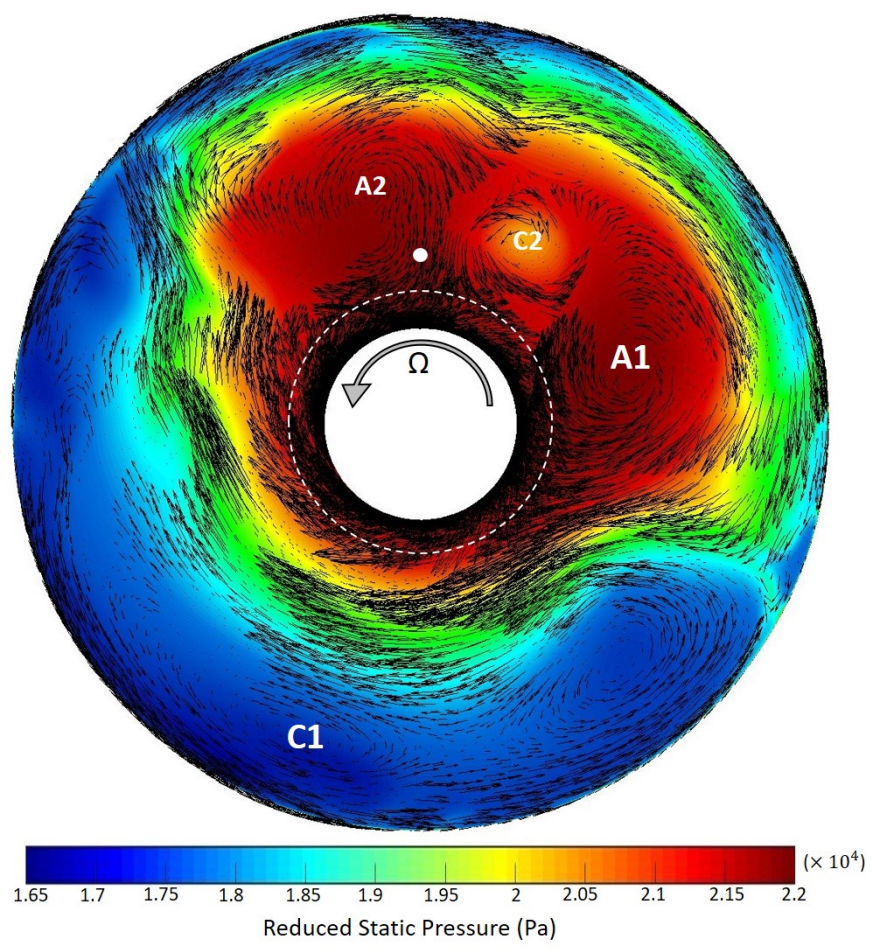

FIGURE 14: Computed incompressible reduced static pressure $[\mathrm{Pa}]$ with relative velocity vectors $\left[\mathrm{ms}^{-1}\right]\left(50^{\text {th }} \mathrm{rev}\right): R o=0.16$, $R e_{\mathrm{z}}=2.4 \times 10^{4}, R e_{\theta}=2.83 \times 10^{6}$ and $\beta \Delta T=0.34$ at cavity mid-plane $(z / s=0.5)$

Farthing et al. [3] measured the variation of the Swirl number $\left(X_{\mathrm{k}}\right)$ against Rossby number $(R o)$ for a heated cavity with $G=$ $0.24,4 \times 10^{5}<\operatorname{Re}_{\theta}<8 \times 10^{5}, 0.5<R o<5$ and, $r / b=0.63$. They found that as the Rossby number is increased from 0.5 to 2 , the $X_{\mathrm{k}}$ value decreased below 1 suggesting less than solid body rotation $\left(V_{\theta}<\Omega r\right)$. This will increase the slip between the disc and the rotating core of the fluid. Figure 15 shows the comparison of the slip at each case with the solid body rotation as obtained from the spectral analysis of $V_{\theta}$ conducted at the cavity mid-axial plane corresponding to $r / b$ value of 0.4 . As seen in Figure 15, the rotational speed is doubled each time $(\Omega=2,4$ and $8 k R P M$ ) and the flow velocity decreased as the Rossby number increased from 0.16 to 0.64 . However there is an exception in the middle rotational Reynolds number that has approximately the same amount of slip as for the highest Reynolds number case. For the lowest rotational number tested (corresponding to 2000 $R P M$ and $R o=0.64$ ) the slip can be as high as $11 \%$. Although spectral analysis was conducted at other radii across all test cases, similar result were found as presented in Figure 15.

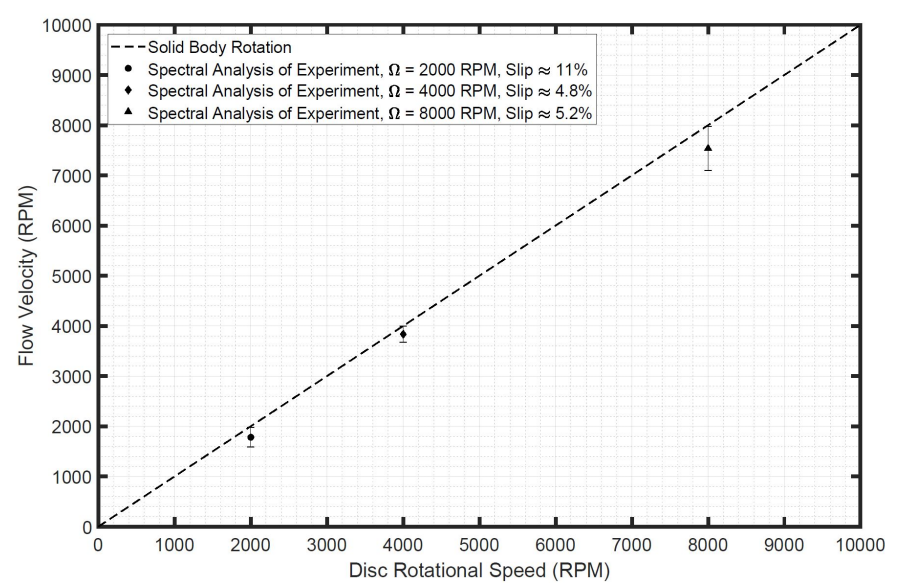

FIGURE 15: Comparison of the slip with solid body rotation, $R e_{\mathrm{Z}}=2.4 \times 10^{4}, 7 \times 10^{5}<\operatorname{Re}_{\theta}<2.83 \times 10^{6}$ at cavity mid-plane $(z / s=0.5)$ at $r / b=0.4$

\section{NUMERICAL RESULTS}

The non-dimensional parameters for all results discussed in this section are as follows: $R o=0.16, R e_{\mathrm{z}}=2.4 \times 10^{4}, R e_{\theta}=$ $2.83 \times 10^{6}$ and $\beta \Delta T=0.34$. They are shown at cavity mid-plane $(z / s=0.5)$ between discs 3 and 4 . The results are discussed to describe the evolution of flow for time-steps corresponding to 30,40 and 50 revolutions of the rotor. In each figure the dashed black circle represents the radial location of the cavity bore to facilitate the flow structure observations. The sense of rotation is anticyclonic.

The reduced static pressure in the $r-\phi$ plane of cavity 3 is shown in Figure $16(\mathrm{a}, \mathrm{b}$, and $\mathrm{c})$. The reduced static pressure,$P^{*}$, is defined as:

$$
P^{*}=P-\frac{1}{2} \rho \Omega^{2} r^{2}
$$

The cyclonic and anticyclonic circulations are the regions where $P^{*}$ is low and high respectively. The results shown in Figure 16(a, b, and c), have encouraging similarities in the flow field observed by [3].

As seen in Figure 16a, a pair of vortices is clearly visible at the time step corresponding to the $30^{\text {th }}$ revolution. A single large cyclonic circulation that is denoted by low pressure region $(\mathrm{C} 1)$ 


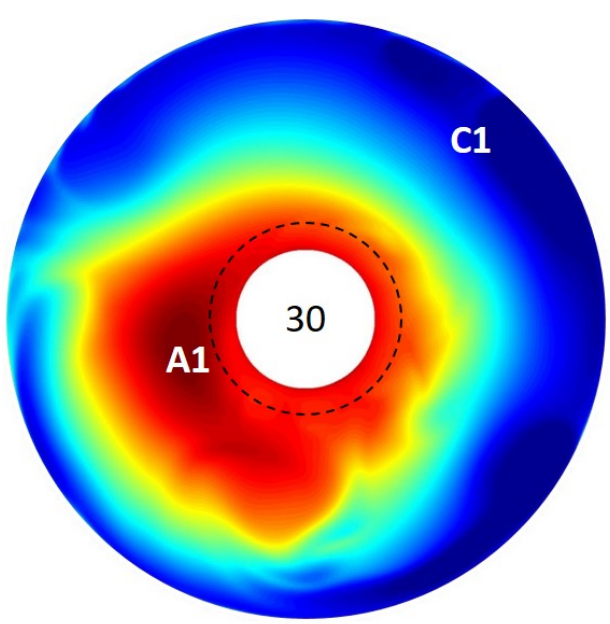

(a)

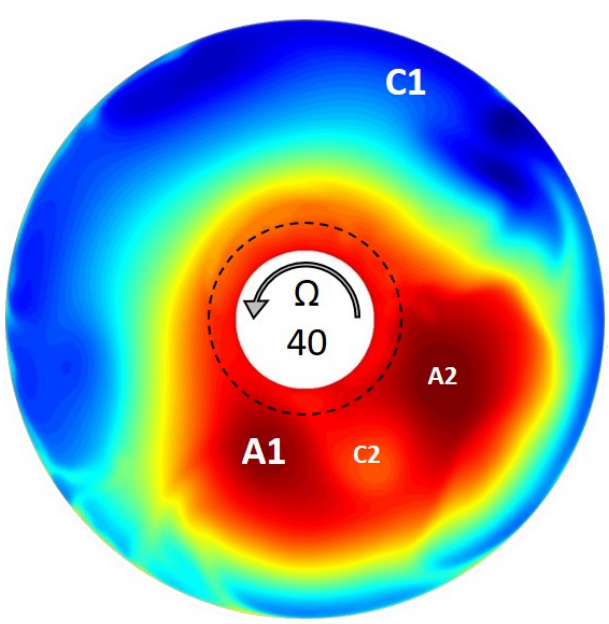

(b)

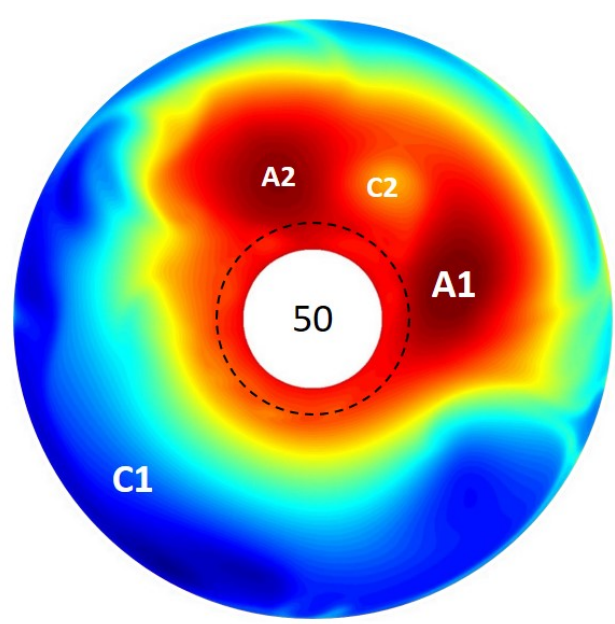

(c)

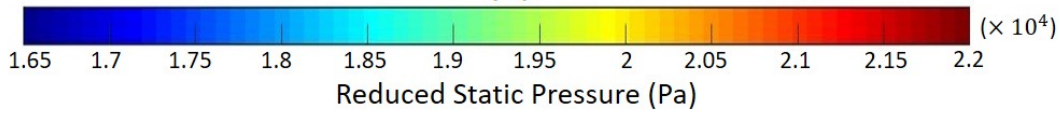

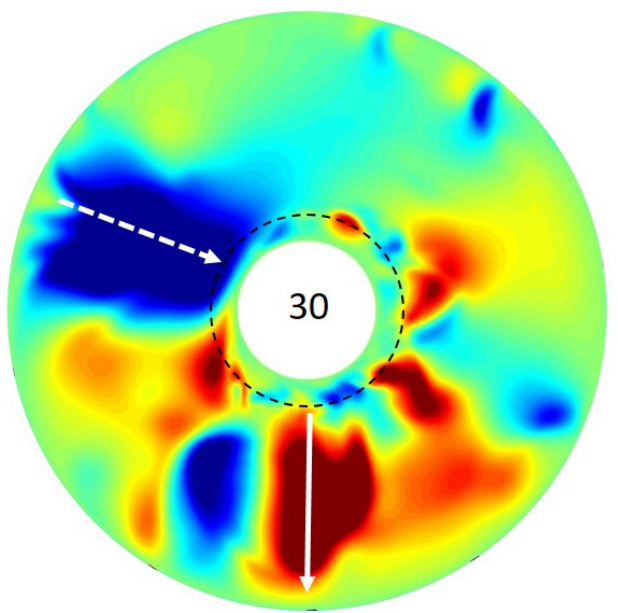

(d)

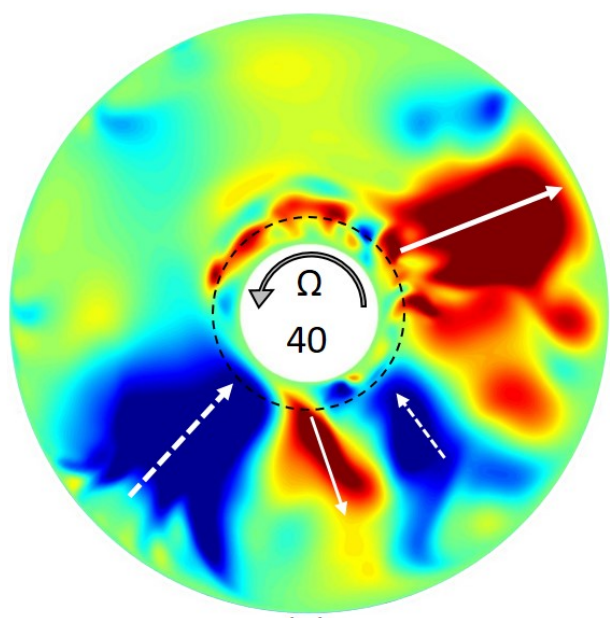

(e)

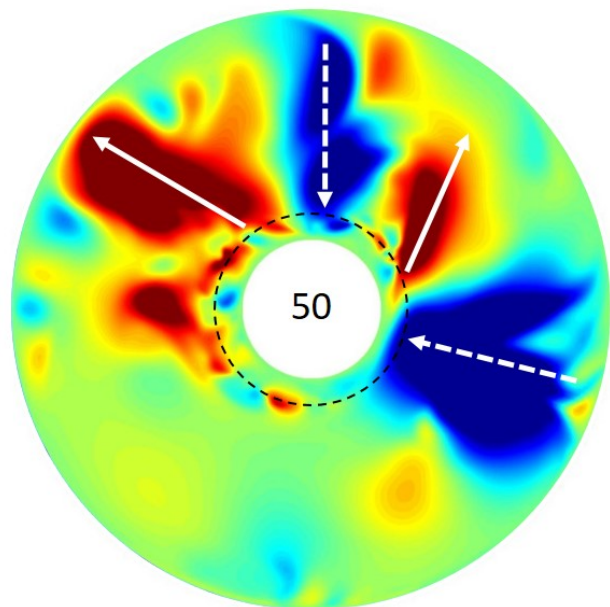

(f)

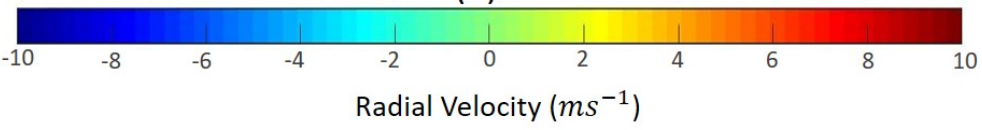

mid-plane (evolution of the number of vortices by passing time)

north-east of the figure interacts with an anticyclonic circulation in south-west of the figure as denoted by high pressure region (A1). In Figure 16b which corresponds to the time step of the $40^{\text {th }}$ revolution, two vortex pairs can be seen. A strong cyclonic circulation $(\mathrm{C} 1)$ which is paired with a strong anticyclonic located in the south-west of the cavity (A1) and a pair of weak vortices that are paired together in the approximately south-east of the cavity (A2 and $\mathrm{C} 2$ ). By the $50^{\text {th }}$ revolution of the disc as shown in Figure 16c, these two vortex pairs are strongly visible and well established.

Owen [22] suggested a relationship between $N$, the number of pairs of vortices and the cavity radius ratio, $a / b$, as follows:

$$
\frac{a}{b}=\frac{2 N-\pi}{2 N+\pi}
$$

With a cavity radius ratio of $\approx 0.32$ for the current research cavity, the above model predicts 3 pairs of vortices. Although this is a reasonable agreement this may suggest that the number of vortices could evolve further with time. The unsteady and unstable nature of the flow structure within the cavity is confirmed by various researchers including [9,20,21]. Figure 16(d, e, and f) represents the radial velocity in the relative frame of reference 
for the same three times as for the reduced static pressure field . The cyclonic and anticyclonic circulations can be assumed to create the circumferential pressure gradient necessary for the air to enter and to leave the cavity. The evolution of the reduced static pressure as shown in Figure 16(a, b, and c) demonstrates the existence a number of pairs of vortices that change with time.

The centres of the low and high reduced static pressure regions can also be seen in the radial velocity plots as regions of increased shear in the radial direction (i.e. adjacent regions of high positive and negative radial velocities). However, there seems to exist more than two such regions of high shear around the bore, some of which are weaker and shorter in radial extent than others (for e.g. in Figure 16d). This suggests that not all regions of radial shear develop into cyclonic and anticyclonic systems that drive radial fluid arms extending from bore to shroud. It may be that the weaker structures are therefore originating from the breakdown of flow near the cavity bore interface. As the cavity flow evolves through more revolutions, the stronger regions of shear emerge as cyclonic and anticyclonic structure that sets up Rayleigh-Bénard like cells in the $r-\phi$ plane. As noted by Atkins et al. [9] there is evidence that these circulating structures can not only carry fluid radially outward from bore to the shroud, but also bring hot fluid from the shroud to the bore region. For example in Figure 16f in the south-east a very strong radial inflow exists, extending from the shroud all the way to the bore. This is complemented by a strong radial outflow (in the north-west). Values of the static temperature in these regions are consistent with a cool outflow (310 to $340 \mathrm{~K}$ ) and a hot inflow (340 to $360 K$ ).

\section{CONCLUSIONS}

This paper has presented experimental measurements from the MCR at University of Sussex. LDA measurements were made of the axial and the tangential velocity components from a heated multiple cavity rig with an axial throughflow of cooling air at engine representative conditions. The experiments have been conducted at ten different operating conditions of which five are reported in this paper as shown in Figure 4. Measurements were conducted over a range of non-dimensional parameters of Rossby, rotational and axial Reynolds numbers, $R o, R e_{\theta}$ and $R e_{\mathrm{Z}}: 0.08<R o<0.64,7 \times 10^{5}<R e_{\theta}<2.83 \times 10^{6}$, $1.2 \times 10^{4}<\operatorname{Rez}<4.8 \times 10^{4}$ and for values of the buoyancy parameter $\beta \Delta \mathrm{T}, 0.284<\beta \Delta T<0.55$. The focus of LDA measurements of tangential and axial velocity components is on the bore region and the cavity mouth. However the mid plane of cavity 3 from shaft up to shroud is also presented. FFT spectral analysis of tangential velocity for various rotational speeds have been also performed.

The specific conclusions arising from the work are :

- The $X_{\mathrm{k}}$ value is near the solid body rotation in two places, firstly near the cob region and secondly when the flow is close to the shroud $r / b>0.8$. In the mouth of cavity $(r / b<$ 0.4 ), swirl value $<1$ on the upstream side and $X_{\mathrm{k}}>1$ on the downstream side. This implies a radial outflow adjacent to the downstream side and conversely a radial inflow next to the upstream side.

- The axial velocity does not vary significantly inside the cavity and remains close to zero, however, for one case there is an axial component at $r / b=0.8$. Flow travels with the expected bulk motion velocity along the bore $\left(V_{\mathrm{z}} / W \approx 1\right)$ and the level of flow unsteadiness in the bore region has a direct relationship with the magnitude of the throughflow.

- The spectral analysis show a spike which has approximately double the magnitude of the frequency of disc rotational speed in all cases that implies the existence of at least two pairs of vortices in the cavity. The number of pairs could change with time and CFD simulations supports this.

- The non-dimensional temperature shows linear and nonlinear variations at specific radial locations on the upstream and downstream faces of a cavity. This might indicate the flow travelling directions as well as different flow structures at different radial locations.

3D unsteady CFD analysis using Fluent with SST k- $\omega$ turbulence model have been performed to determine the flow structure in the cavity and compare this with velocity measurements. Two different operating conditions have been used for CFD simulations. The non-dimensional parameters for numerical results discussed in this paper are as follows: $0.16<R o<0.32, R e_{\mathrm{Z}}=2.4 \times 10^{4}$, $1.4 \times 10^{6}<\operatorname{Re}_{\theta}<2.83 \times 10^{6}$ and $0.34<\beta \Delta T<0.38$.

- For the axial velocity, the numerical results show good agreement with the corresponding LDA measurements suggesting that the turbulence model can be used with acceptable level of confidence to illustrate the flow structure in detail and to show the flow unsteadiness and instability.

- The flow field predictions show an evolution in number of vortex pairs in time. At specific time step, two pairs of vortices are captured indicating good agreement with the spectral analysis data. However, the number of pairs could change with time.

- The Rayleigh-Bénard like cells are captured in the $r-\phi$ plane that are created by buoyancy induced flow in rotating cavities. The computational results show that these circulating structures are able to carry cold fluid radially outward from bore to shroud and hot fluid radially inward from shroud to bore.

\section{ACKNOWLEDGMENT}

The authors would like to thank Mr. Harri Koivisto for his permission to use his in-house MATLAB code to help visualise 
the flow field. We also would like to thank Mr. Simon Davies our technician in TFMRC for his invaluable and kind help and assistance.

\section{REFERENCES}

[1] Farthing, P. R., Long, C. A., Owen, J. M., and Pincombe, J. R., 1992. "Rotating cavity with axial throughflow of cooling air: Heat transfer". ASME J.Turbomach, 1(114), January, pp. 229-236.

[2] Alexiou, A., 2000. "Flow and heat transfer in gas turbine H.P Compressor internal air systems". PhD Thesis, University of Sussex, Falmer, April.

[3] Farthing, P. R., Long, C. A., Owen, J. M., and Pincombe, J. R., 1992. "Rotating cavity with axial throughflow of cooling air: Flow structure". ASME J.Turbomach, 1(114), January, pp. 237-246.

[4] Bohn, D. E., Deutsch, G. N., Simon, B., and Burkhardt, C., 2000. "Flow Visualisation in a Rotating Cavity with Axial Throughflow". ASME Paper No. 2000-GT-0280, pp. 1-8.

[5] Alexiou, A., Long, C.A., Turner, A.B., and Millward, J.A., 2000. "Heat transfer in high-pressure compressor gas turbine internal air systems: a rotating disc-cone cavity with axial throughflow". Experimental Heat Transfer 13(4).

[6] Long, C.A., Alexiou, A., and Smout, P.D, 2003. "Heat Transfer in H.P. Compressor Gas Turbine Internal Air Systems Measurements from the Peripheral Shroud of a Rotating Cavity with Axial Throughflow". 2nd International Conference on Heat Transfer, Fluid Mechanics and Thermodynamics (HEFAT).

[7] Owen, J. M., Powell, J., 2004. "Buoyancy-Induced Flow in a Heated Rotating Cavity". ASME Paper No. GT200453210.

[8] Long, C. A., Miché, N.D.D., and Childs, P.R.N., 2007. "Flow measurements inside a heated multiple rotating cavity with axial throughflow". International Journal of Heat and Fluid Flow, pp. 1391-1404.

[9] Atkins, N. R., Kanjirakkad, V., 2014. "Flow in a Rotating Cavity with Axial Throughflow at Engine Representative Conditions". ASME Paper No. GT2014-27174, pp. 1-14.

[10] Owen, J. M., Long, C. A., 2015. "Review of buoyancyinduced flow in rotating cavities". ASME J.Turbomach, 137(11), p. 111001.

[11] Tang, H., Owen, J. M., 2017. "Effect of Buoyancy-Induced Rotating Flow on Temperatures of Compressor Disks". ASME J. Eng. Gas Turbines Power, 139(6), p. 062506.

[12] Owen, J. M., Tang, H., 2015. "Theoretical Model of buoyancy-induced flow in rotating cavities". ASME J.Turbomach, 137(11), p. 111005.

[13] Tang, H., Shardlow, T., and Owen, J. M., 2015. "Use of Fin Equation to Calculate Nusselt Numbers for Rotating Discs". ASME J.Turbomach, 137(12), p. 121003.
[14] Puttock-Brown, M.R., Rose, M.G. and Long, C. A., 2017. "Experimental and computational investigation of rayleighbénard flow in the rotating cavities of a core compressor". ASME Paper No. GT2017-64884.

[15] Puttock-Brown, M.R., 2017. "Experimental and Numerical Investigation of Flow Structure and Heat Transfer in Gas Turbine HP Compressor Secondary Air Systems". PhD Thesis, University of Sussex, Falmer, July.

[16] Puttock-Brown, M.R., and Rose, M.G., 2017. "Measurement of thermal wakes in compressor secondary air systems using low frequency thermocouple data". XXIII Biennial Symposium on Measuring Techniques in Turbomachinery, Stuttgart, Germany.

[17] Miché, N.D.D, 2008. "Flow and heat transfer measurements inside a heated multiple rotating cavity with axial throughflow". PhD Thesis, University of Sussex, Falmer, September.

[18] Dweik, Z., Briley, R., Swafford, T., and Hunt, B., 2009. "Computational study of the unsteady flow structure of the buoyancy-driven rotating cavity with axial throughflow of cooling air". ASME Paper No. GT2009-59969.

[19] Dweik, Z., Briley, R., Swafford, T., and Hunt, B., 2009. "Computational study of the heat transfer of the buoyancydriven rotating cavity with axial throughflow of cooling air". ASME Paper No. GT2009-59978.

[20] King, M.P., Wilson, M., and Owen, J.M., 2005. "Rayleigh-Bénard Convection in Open and Closed Rotating Cavities". ASME Paper No. GT2005-68948.

[21] Tian, S., Tao, Z., Ding, S., and Xu, G., 2004. "Investigation of flow and heat transfer in a rotating cavity with axial throughflow of cooling air". ASME Paper No. GT200453525.

[22] Owen, J. M., 2010. "Thermodynamic Analysis of Buoyancy-Induced Flow in Rotating Cavities". ASME J. Turbomach, 132(3), p. 031006. 